\title{
ETV6/RUNX1 fusion gene and its active role
}

\author{
Ahmad Reza Rahnemoon \\ Retired in Hematology Department, Iran University of Medical Sciences, Tehran, Iran.
}

Corresponding Author: Ahmad Reza Rahnemoon, Retired in Hematology Department, Iran University of Medical Sciences, Tehran, Iran, Email: ar.rahnemoon@gmail.com

Received Date: July 20, 2021; Accepted Date: August 06, 2021; Published Date: Augusł 27, 2021

Citation: Ahmad Reza Rahnemoon. (2021). ETV6/RUNX1 fusion gene and its active role. J. Cancer Research and Cellular Therapeutics. 5(4); Doi: 10.31579/2640-1053/091

Copyright: (C) 2021 Ahmad Reza Rahnemoon, This is an open-access article distributed under the terms of the Creative Commons Attribution License, which permits unrestricted use, distribution, and reproduction in any medium, provided the original author and source are credited.

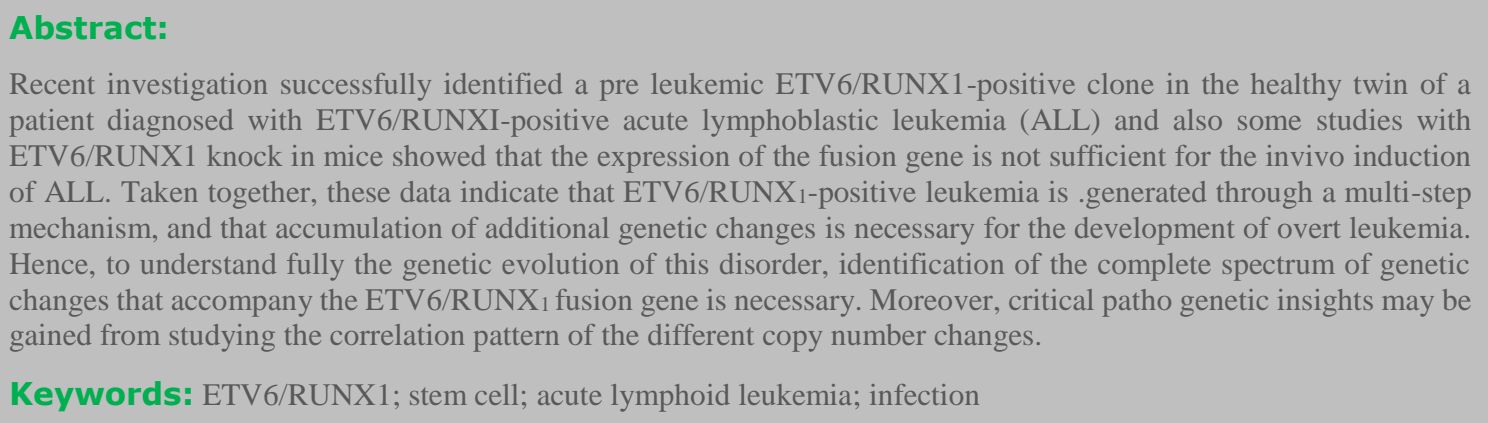

\section{Introduction:}

What might be responsible for the relatively high frequency $(\sim 1 \%)$ of ETV6/RUNX1 fusion generation in normal fetal hematopoiesis? Presumably, nonfunctional fusions (in non-stem cells) occur at an even higher rate. One possibility is that these are 'normal' developmental errors of DNA maintenance reflecting the complexity of embryo and fetal tissue engineering in which cell death, DNA damage and oxidative stress are ubiquitous [2]. The initiation of other pediatric cancers has similarly been ascribed to developmental accidents [9]. Even if ETV6/RUNX1 fusion is, in effect, a spontaneous error, the risk of this event occurring may be modified by other factors. There is dietary and genetic evidence that folate has an impact on the risk of infant and childhood leukemia, and this could well be operative during pregnancy in utero, influencing the likelihood of chromosomal breaks.

\section{Discussion:}

Acute lymphoblastic leukemia (ALL) is defined by recurrent chromosomal aberrations. The vast majority of cases belong to the B cell precursor subtype. Many of these aberrations originate in utero and the cells transform in early childhood. Actually infant ALL with KMT2A rearrangements as well as childhood ALL is caused by a combination of genetic susceptibility factors and also acquired somatic mutations subsequently. The mutations happen in genes generally which are critical for lymphoid development. The first hit of secondary change produces a pre-leukemic state. In fact, it is widely accepted that leukemia with gene fusions can occur before birth. For example, in twins with ETV6/RUNX1, the ALL development can occur at different times, and the postnatal latency can be protracted occasionally and variable too [20,27].

General observations: Some studies indicated that although ETV6/RUNX1 may be linked to early pre leukemia clonal expansion, it is insufficient for overt ALL. First, the protracted postnatal interval, or latency, before disease diagnosis can be up to a decade or more [4] and concordance rates in twins are modest at $\sim 10 \%$ [1]. This suggests that additional or secondary and complementary genetic events are required. Second, frequency of 'functional' ETV6/RUNX1 fusions in normal newborns is $\sim 100 \times$ the leukemia rate This interpretation accords with conventional wisdom in two- or multistep models of cancer clone evolution [5] and also fits with results from transgenic modeling with fusion genes. There might not be an exclusive second genetic 'hit' but at diagnosis most cases of ALL with ETV6/RUNX1 fusions have deletion of the non-rearranged or normal ETV6 allele. Deletions are sub clonal to ETV6/RUNX1 fusions and are distinct in their genomic boundaries in twins, and in relapse versus diagnostic samples from the same individuals [6]. ETV6 deletions are therefore likely to be postnatal secondary events, albeit a common and integral component of the molecular pathogenesis of cALL. Deletion of normal ETV6 must have some potent selective advantage in cells carrying ETV6/RUNX1 fusions, which might relate either to a suppressor function of ETV6 [7] and/or to the ability of normal ETV6 protein to dimerize with ETV6/RUNX1 and reduce its transforming activity. One intriguing proposal, with therapeutic implications, is that fusion genes encoding hybrid transcription factors such as ETV6/RUNX1 also require genetic complementation with mutant or activated kinases [8] Activated kinases could interfere with the cell cycle and complement the differentiation-blocking activity of chimeric 
transcription factors. Whether ETV6 deletion itself is sufficient to dys regulate the cell cycle in this way remains to be assessed.

Gene RUNX1 (AML1) or CBFA2 is located in the chromosome band 21q22. Its product makes up a transcription factor as well, that binds the sequence TGT/cGGT. This affinity intensifies consequently hetero dimerization with the $\mathrm{CBF} \beta$ protein forming a complex called human core-binding factor (CBF). The activity of this complex is critical during the expression of genes specific for hematopoiesis. RUNX1 is normally expressed in all hematopoietic lineages and acts to regulate the expression of various genes such as: the granulocyte colony stimulating factor, interleukin 3, T cell receptor $\beta$ and myeloperoxidase (MPO) genes [15]. A high level of expression of RUNX1 is limited to cells of the hematopoietic lineage and to ganglion cells of the developing nervous system. These properties are a result of protein structure encoded by RUNX1 gene. This one has highly homologous to the Drosophila RUNT domain (118 amino acids) at N-terminus which interacts with DNA and $\mathrm{CBF} \beta$, however at $\mathrm{C}$-terminus-transactivation domain (TA). The former domain is strictly conserved in fusions proteins coming from the chromosomal changes in which RUNX1 gene participates [1-8].

Breakpoints are scattered throughout the $12 \mathrm{~kb}$ intron 5 of ETV6 and the $\sim 100 \mathrm{~kb}$ intron 1 on $\mathrm{AML}_{1}$. Statistically, there is some degree of micro clustering, but critically, each patient's leukemic cells have unique, or clonotypic, breakpoints. The sharing of the same unique clonotypic ETV6/RUNX1 genomic breakpoints and fusion sequences between twins (and that are acquired not constitutive) indicates a single-cell origin. Concordance of disease then arises via spread of clonal progeny from one twin, in which the translocation arises, to the other prenatally via vascular anastomoses within a mono chorionic placenta. These data are endorsed by the detection of putative pre leukemic B-lineage cells in normal cord blood that harbor ETV6/RUNX1 translocations [1-4].

The fusion gene origin: Actually, a greater number of healthy individuals can harbor at some fusion genes as a silent pre-leukemic clone. But Why and/or how? Moreover, these rearrangements could arise in high proportion of developing fetuses, but without any functional chimeric proteins production, also their originate is an inappropriate with cellular context alternatively In other words, in producing a leukemic phenotype, we have two conditions includes 1) Gene fusion structure must permit to functional protein production [2]. The translocation should happen in early precursors with self- renewal ability. So, some researcher stated that in normal individuals, fused genes arise in mature precursors or in differentiated cells which eliminated by cell differentiation normal mechanisms. But how? Or generally, is this right? Also, if somebody believed that the immune system power to recognize and eliminate the cells that express the rearrangement, so why do not ability to the same action in other patients? Some authors suggested that tumor associated translocations in peripheral lymphocytes can be transitory or the rearrangement expressed in hematopoietic cells which entered in the apoptotic pathway, now can be as an irrelevant in mature cells. What does it mean exactly? Also, it is possible that fusion genes associate with previous exposure to diverse exogenous as well as endogenous sources which can consider as the physical and chemical agents in comparing with other cell types [16-19, 27].

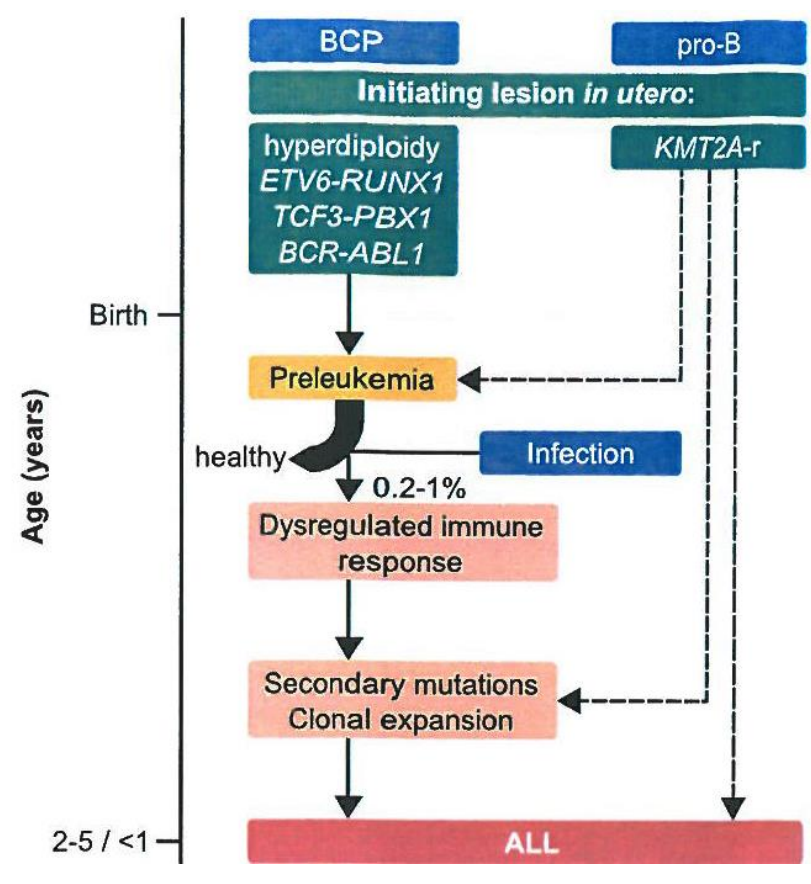

Figure 1: ETV6/RUNXI (pre-leukemia), infection and then ALL: Expression of ETV6/RUNXI alone can mimic the pre leukemic clone but not induce
leukemia in an in vivo model, viz. the identification of clonotypic ETV6/RUNX1 genomic sequences in neonatal blood spots provides direct evidence
for the existence of the fusion gene at birth, also it may be the first or initiating event in most cases. In other words, the initiating lesions happen in
utero and lead to a state of pre-leukemic after birth. We must know that the infection agent can lead to deregulated immune response in a little of
pre-leukemic childhood, however most of them remain healthy.

But the important question is how infection can lead into leukemic condition? [3, 20] Please look at the figures $2 \& 3$.

Anyhow, we can say, ETV6/RUNX1 is seen in healthy individuals especially newborns. Therefore, the fusion gene is not sufficient for leukemia development only, so secondary postnatal mutations are necessary (figures 1, 2\&3). Some researchers believe that leukemia associated fusion genes before birth. They say, in twins with concordant ETV6/RUNX1 positive leukemia, the development of ALL has been found to occur at different times, and postnatal latency can be variable and occasionally protracted; or somebody say ,ETV6/RUNX1 translocation occurs in utero, followed by pre-leukemic evolution. 
The first cells produced, embryonic (or primitive) erythrocytes arise within the blood islands of the yolk sac at embryonic day 14. Later hematopoiesis shifts to the fetal liver and to spleen where adult red cells, as well as cells of other lineages appear- the process of granulo-, monolymph- and megakaryocytopoiesis starts. The development ends in bone marrow and in lymphatic nodes. The regulation of these processes takes place at multiple levels to ensure proper blood cells proliferation, differentiation and survival of progenitor's cells. One of them is operation of cytokines, their receptors and the transcriptional factors, affecting the correct genes expression. Thus, initiation of angiogenesis in the yolk sac, maintenance of life cells, their proper movement from fetal liver and spleen to bone marrow and processes, which work there, are controlled by ETV6 gene. However, ETV6 is not intrinsically required for the growth or differentiation of hematopoietic cells [10-14]. In spite of these facts, the disorder in adhesion and colonization of ETV6 $6^{-1-}$ HSCs (or progenitors) in microenvironment of bone marrow may reflect the subsequent appearance and circulation in the peripheral blood of premature leukemic progenitors which proliferate excessively. This constitutes a very important element in pathogenesis of ETV6/RUNX1 because the ETV6 loss impairs the progenitor's capacity for effective hematopoiesis in the boon marrow [12].

\section{Conclusion:}

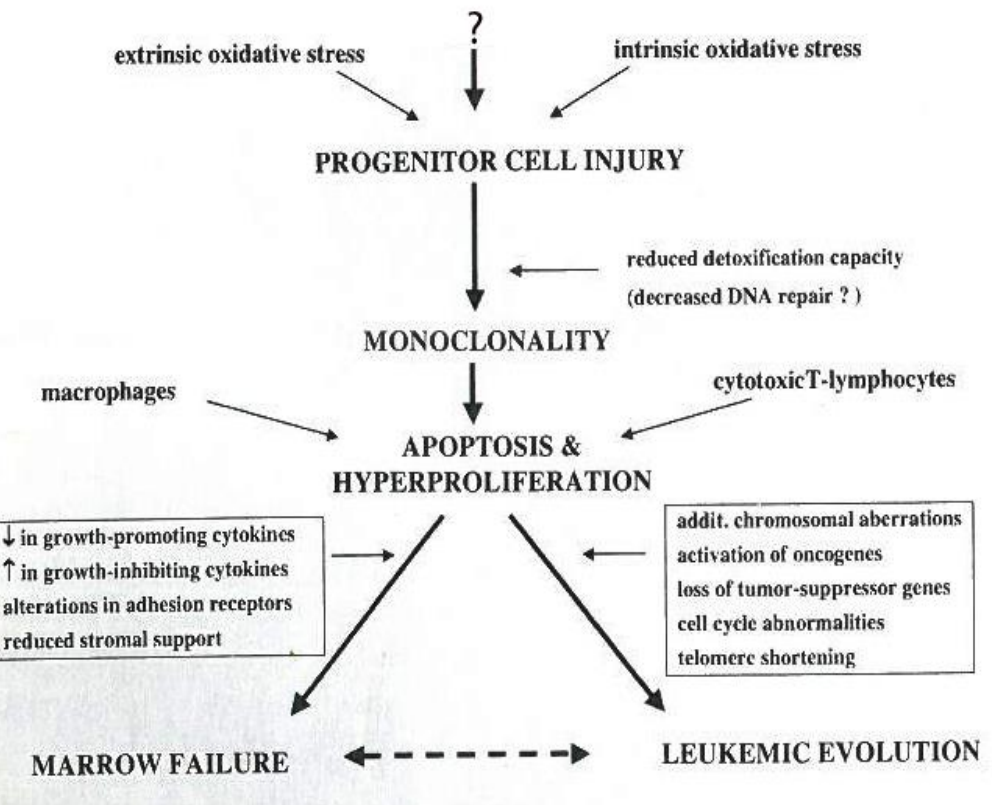

Figure 2: After extrinsic or intrinsic oxidative stress and/or "other cancerous agents: look at the progenitor cell injury.

Now, the interpretation of figure 1 at after the pre-leukemic condition can be as follows: the action of ETV6/RUNX1 producing a protein that destruct the normal cell and change the HSC to LSC $\left(1^{\text {st }}\right.$ hit $)$, After the monoclonality stage (clonal expansion) and hyper-proliferation as well which normal cells differentiation is ruined and may be in $2^{\text {nd }}$ hit(chromosomal aberrations, activation of oncogenes, etc.), we see the unlimited phase that can be a severely marrow failure or the leukemic cells increased( cancerous stage and/or leukemic evolution). So feedback of this model in leukemic bone marrow niche, HSC maintenance is decreased. In the pathway, BM microenvironment should be disrupted partially or completely and impaired the normal cells production severely figure 2 [19-22, 24].

Whatever the mechanisms governing chromosomal changes in utero, it is evident that for most cases of childhood leukemia, the crucial etiologic bottleneck is the postnatal 'promotional' events or exposures that precipitate the secondary genetic changes, including TEL deletion. In fact, there is a convincing evidence that a significant percentage of the pre-leukemic lesions can arise prenatally and it's changing in after postnatal secondary occurring process. The first hit occurs in the cell of origin which differs from subtype to subtype, such as ETV6/RUNX1 seem to arise in B cell development (not at earliest stage) but the exact stage of cell is unknown. In this case, infection, delayed infection or other instances are absolutely propounded (figure 1). Also, populations mixing can be as a leukemic transformation factor. But the important factor is infection (figure 3) which can be as a trigger the progression of preleukemia to acute leukemia like ALL [20-25]. 


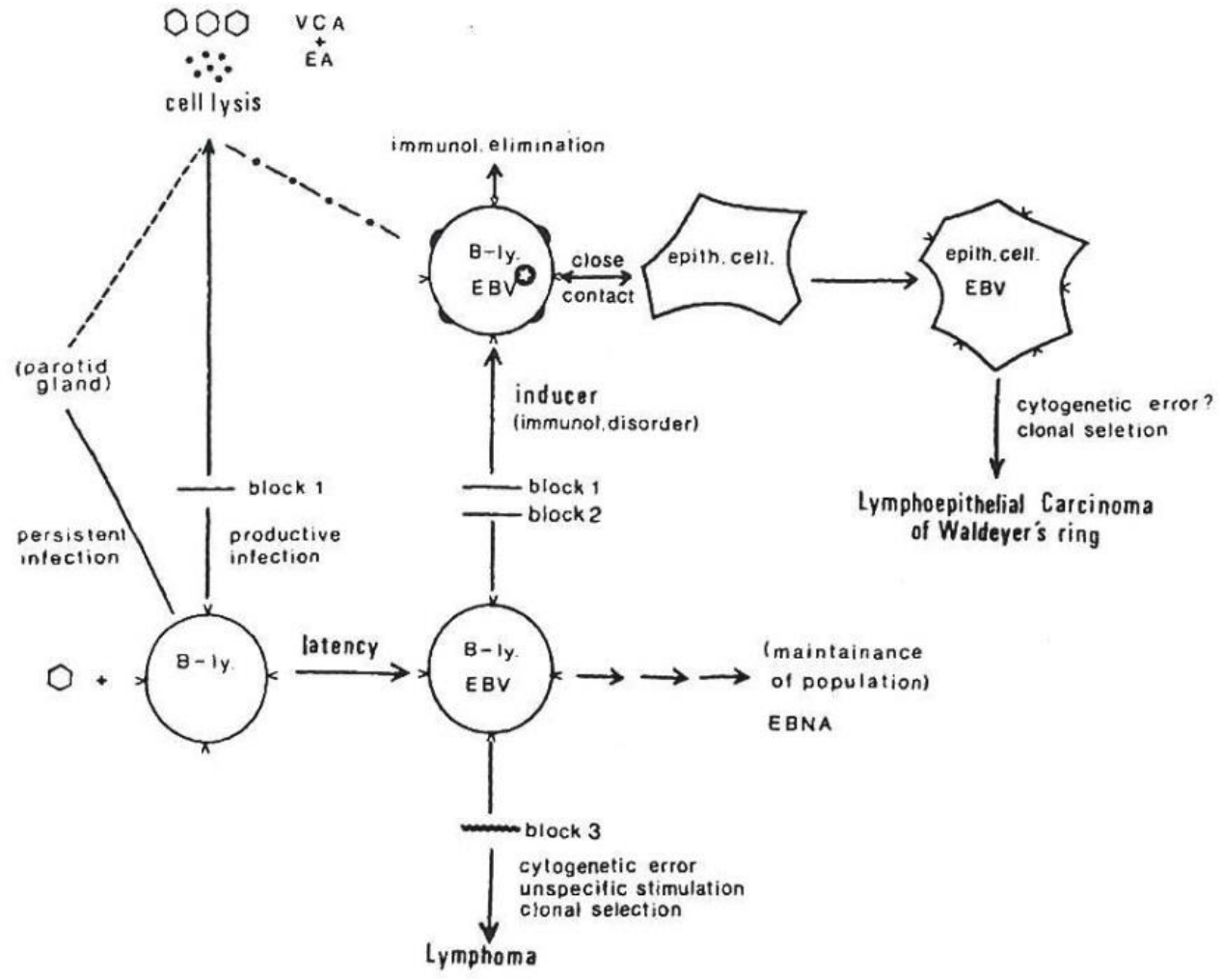

Figure 3: B-lymph EBV, cytogenetic error and then Burkitt's lymphoma (or NPC): Including two malignant diseases: 1) Burkitt's lymphoma (BL). 2) Nasopharyngeal carcinoma $(N P C)$.

Now, we want to find that why EBV (Epstein Barr virus) can change to malignancy? In response and in the development of nasopharyngeal carcinoma, a close contact between epithelial cells and B- lymphocytes that may carry EBV genomes, and after EBV induced fusion between the two cell types, now EBV genome enable to enter the epithelial cells(epithelial, EBV). Look at the blocks 1(at cellular level in endogenous block) and block 2(in outside or exogenous block) inhibit the lytic expression of EBV. (Please give attention to figure 1 at pre-leukemic condition and infection role in the matter as well). On the other hand, the clone may lead to the development of BL. We know that block 3 suppresses the proliferation of EBV genome containing lymphoid cells in the periphery. Please look at the pathway of lymphoma in B-cell, EBV(Blymph- EBV) as well as some factors role like cytogenetic error , unspecific stimulation or clonal selection in changing to lymphoma [1920, 23-26].

\section{References:}

1. Greaves MF, Maia AT, et al. (2003) Leukemia in twins: lessons in natural history. Blood. 102(7):2321-2333.

2. Greaves MF, Wiemels J. (2003) Origins of chromosome translocations in childhood leukemia. Nat. Rev. Cancer. 3(9):639649.

3. Hjalgrim LL, Madsen HO, et al. (2002) Presence of clone- specific markers at birth in children with ALL. Br. J. Cancer. 87:994-999.

4. Maia AT, Koechling J, et al. (2004) Protracted postnatal natural histories in childhood leukemia. Genes Chromosomes Cancer. 39:335-340.

5. Knudson AG. (1992) Stem cell regulation, tissue ontogeny, and oncogenic events. Semin. Cancer Biol. 3:99-106.
6. Ford AM, Fasching K, et al. (2001) Origins of "late" relapse in childhood ALL with TEL/ AML 1 fusion genes. Blood. 98:558564.

7. Fenrick R, Wang L, et al. (2000) TEL, a putative tumor suppressor, modulates cell growth and cell morphology of ras transformed cells while repressing the transcription of stromelysin 1.Mol. Cell Biol. 20:5828-5839.

8. Speck NA, Gilliland DG. (2002) Core- binding factors in hematopoiesis and leukemia. Nat. Rev. Cancer. 2:502-513.

9. Maris JM, Denny CT. (2002) Focus on embryonal malignancies. Cancer Cell. 2:447-450.

10. Graves BJ, Petersen JM. (1998) Specificity within the ets family transcription factors. Adv Cancer Res. 75:1-55.

11. Wasylyk B, Hahn SL, Giovane A. (1993) The Ets family of transcription factors. Eur J Biochem. 211: 7-18.

12. Wang LC, Swat W, et al. (1998) The TEL/AML 1 gene is required specifically for hematopoiesis in the bone marrow. Genes Dev. 12(15):2392-402.

13. Wiemels JL, Greaves M. (1999) Structure and possible mechanisms of TEL/ AML1 gene fusion in childhood ALL. Cancer Res. 59:4075-82.

14. Yergeau DA, Hetherington CJ, et al. (1997) Embryonic lethality and impairment of hematopoiesis in mice heterozygous for AML1-ETO fusion gene. Natl. Genet. 15:303-306.

15. Panther $\mathrm{D}$, preudhomme $\mathrm{C}$, et al. Amplification of $\mathrm{AML}_{1}$ gene is present in childhood ALL but not in adult, and is not associated with $\mathrm{AML}_{1}$ gene mutation.

16. Bose S, et al. (1998) The presence of typical and atypical BCR/ABL fusion genesin leukocytes in normal individuals: biological significance and implications for the assessment of minimal residual disease. Blood. 92:3362-3367. 
17. Nakamura N, et al. (2005) A hypothesis: radiation related leukemia is mainly attributable to the small number of people who carry pre-exiting clonally expanded pre-leukemic cells. Radiat. Res. 163:258-265.

18. Tucker JD, et al. (1996) chromosome aberrations, micronuclei, aneuploidy, sister chromatid exchange, and cancer risk assessment. Mutat. Res. 365: 147-159.

19. Brassesco MS. (2008) Leukemia/lymphoma associated gene fusions in normal individuals. GMR. 7:782-790.

20. Hein D, et al. (2020) insights into the prenatal origin of childhood acute lymphoblastic leukemia. Cancer Metastasis Rev. 39:161171.

21. Schafer D, et al. (2018) Five percent of healthy newborns have an ETV6/RUNX1 fusion as revealed by DNA based GIPFEL screening. Blood. 131:821-826.

22. Hein D, et al. (2019) The pre-leukemic TCF3-PBX1 gene fusion can be generated in utero and is present in about $(\sim) 0.6 \%$ of healthy newborns. Blood. 134: 13355-1358.

23. Wolf H, et al. (1984) Benign and malignant disease caused by EBV (EBV related disease). The Journal of Investigative Dermatology. 83(S):88-95

24. Delforge M. (2003) Understanding the pathogenesis of myelodysplastic syndromes. The Hematology Journal. 4-303-309.

25. Martin-Lorenzo A, et al. (2015) Infection exposure is a causal factor in B-cell precursor acute lymphoblastic leukemia as a result of Pax5-inherited susceptibility. Cancer Discovery. 5:1328-1343.

26. Rodriguez- Harnandez G, et al. (2017) Infection exposure promotes ETV6/RUNX1 precursor B cell leukemia via impaired H3K4 Demethylases. Cancer Research. 77:4365-4377.

27. Vora A. (2016) Childhood acute lymphoblastic leukemia. In Hoffbrand AV, et al. Postgraduate Hematology, Seventh edition, Willey Blackwell. 22:384-398.

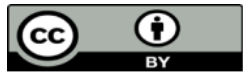

This work is licensed under Creative Commons Attribution 4.0 License

To Submit Your Article Click Here: Submit Article

\author{
Ready to submit your research? Choose Auctores and benefit from: \\ * fast, convenient online submission \\ * rigorous peer review by experienced research in your field \\ * rapid publication on acceptance \\ * authors retain copyrights \\ * unique DOI for all articles \\ * immediate, unrestricted online access
}

At Auctores, research is always in progress.

Learn more www.auctoresonline.org/journals/cancer-research-andcellular-therapeutics 